\title{
Effect of Nano-Oxide Particle Size on Radiation Resistance of Iron-Chromium Alloys
}

\author{
Weizong $\mathrm{Xu}^{\mathrm{a}}$, Lulu $\mathrm{Li}^{\mathrm{a}}$, James A. Valdez ${ }^{\mathrm{b}}$, Mostafa Saber ${ }^{\mathrm{c}}$, Yuntian Zhu ${ }^{\mathrm{a}^{*}}$, Carl C. \\ Koch $^{\mathrm{a}}$, Ronald O. Scattergood ${ }^{\mathrm{a}}$
}

${ }^{a}$ Department of Materials Science and Engineering, North Carolina State University, Raleigh, NC 27695, USA

${ }^{b}$ Materials Science and Technology Division, Los Alamos National Laboratory, Los Alamos, New Mexico 87545, USA

${ }^{c}$ Department of Mechanical and Materials Engineering, Portland State University,

Portland, Oregon 97201, USA

\begin{abstract}
Radiation resistance of $\mathrm{Fe}-14 \mathrm{Cr}$ alloys under $200 \mathrm{keV}$ He irradiation at $500{ }^{\circ} \mathrm{C}$ was systematically investigated with varying sizes of nano oxide $\mathrm{Zr}$, $\mathrm{Hf}$ and $\mathrm{Cr}$ particles. It is found that these nano oxide particles acted as effective sites for He bubble formation. By statistically analyzing 700-1500 He bubbles at the depth of about 150-700 $\mathrm{nm}$ from a series of HRTEM images for each sample, we established the variation of average He bubble size, He bubble density, and swelling percentage along the depth, and found them to be consistent with the He concentration profile calculated from the SIRM program. Oxide particles with sizes less than 3.5-4 nm are found most effective for enhancing radiation resistance in the studied alloy systems.
\end{abstract}

Keywords: He bubble, irradiation, nano-oxide, void swelling

Correspondence and requests for materials should be addressed to Yuntian Zhu (email: ytzhu@ncsu.edu) 


\section{Introduction}

One of the key ingredients in engineering irradiation tolerant materials is through the use of nano-size particles (or dispersoids) [1-7]. This has been demonstrated by Y-Ti-enriched nano-oxides, which are found to enhance the irradiation resistance and creep strength of oxide dispersion strengthened (ODS) alloys at elevated temperatures[3, 5, 8-10]. The nano-oxide particles not only provide large fractions of interfaces for vacancy and self-interstitial recombination, but also serve as preferential trapping sites for helium [11-15]. Helium, as an unavoidable byproduct from neutron-induced $(n, \alpha)$ transmutation reactions in the nuclear reactor environment, is insoluble in ferritic alloys and has the potential to deteriorate materials via void swelling, blistering or embrittlement upon their accumulation [16]. These adverse effects are found to be minimized by the incorporation of nano-oxides in the microstructure to trap helium in fine-scale bubbles[16-21]. Therefore, understanding the effect of nano-oxide particles and their interaction with helium in the irradiation environment becomes a critical factor in designing irradiation resistant materials for nuclear applications.

Current studies of nano-size oxide particles are mostly focused on Y-Ti-enriched oxides in ODS alloys. They are incorporated into the ferritic alloy via mechanical alloying with 0.2-0.3 wt.\% $\mathrm{Y}_{2} \mathrm{O}_{3}$ and $\sim 0.2$ wt.\% $\mathrm{Ti}[1,3,5,22-29]$, and subsequent heating in the temperature range of $1000-1150{ }^{\circ} \mathrm{C}[3,30]$. The addition of Ti particles helps to refine the oxide size down to about 1-15 $\mathrm{nm}$ by forming complex 
non-stoichiometric Y-Ti-enriched oxides. The suppression of nano-oxide particles on swelling and embrittlement is largely attributed to its strong He trapping capability $[17,28,31,32]$. This scenario is directly supported by transmission electron microscopy (TEM) observations from[17, 31], indicating that small He bubbles are preferentially formed at the metal-oxide interfaces. A recent APT study by Edmondson et al. revealed that the coverage of $\mathrm{He}$ atoms on the nano-oxide particle interfaces can be as large as 50\% [20]. Such high tendency of He attraction by the oxide interface could be due to the strong interaction between He and vacancy-oxygen at the oxide interface according to the first-principle calculations [33]. Recently, the effectiveness of nano-oxide particles on the promotion of $\mathrm{He}$ bubble formation was examined in ODS alloys. The highly dispersed nano-scale oxide particles were found to be an effective nucleation sites for He bubbles [20]. Smaller bubble sizes and smaller volume fraction occur in ODS alloys containing nano-oxide particles compared to those without them under He irradiation [8].

Recent studies by our group have revealed high densities of nano particles of $\mathrm{ZrO}_{2}$ and $\mathrm{HfO}_{2}$ dispersed in the ferritic matrix $[34,35]$. These particles are in the size range of 1-10 nm, which is comparable to the nano particles in conventional ODS alloys. It is still not clear how effective these nano-size oxide particles are in enhancing irradiation resistance. Here we report a systematic study on He bubble characteristics in six types of Fe-14Cr alloy samples with different oxide particles subjected to 200 $\mathrm{keV} \mathrm{He}$ irradiation. This includes $\mathrm{Fe}-14 \mathrm{Cr}$ alloys with $\mathrm{Zr} / \mathrm{Hf}$ additions as well as 
Fe-14Cr base alloys. Direct microstructural characterization and statistical analysis are performed to reveal the bubble size, bubble density, and swelling percentage in these alloys. The effectiveness of the size of nano oxide particles in enhancing irradiation resistance is systematically studied.

\section{Materials and methods}

2.1 Materials synthesis

Fe-14Cr based alloys were synthesized by mechanical alloying using a SPEX 8000M Mixer/Mill. To produce $\mathrm{Fe}-14 \mathrm{Cr}-1.5 \mathrm{Zr}$ alloys (atom \%), powders of $\mathrm{Fe}, \mathrm{Cr}, \mathrm{Zr}$ (from Alfa Aesar, with 99.9\%, 99.9\%, 99.5\% purity, respectively) were mixed, sealed, and mechanically milled for 20 hours under purified Ar atmosphere (with less than 1 ppm of oxygen and $\mathrm{H}_{2} \mathrm{O}$ ). The ball to powder mass ratio was 10:1. The as-milled powders were then annealed in a quartz tube under a $\mathrm{Ar}-2 \% \mathrm{H}_{2}$ protective atmosphere at $800{ }^{\circ} \mathrm{C}$ and $900{ }^{\circ} \mathrm{C}$ for 1 hour. The starting powder mixture contained excess oxygen according to our previous work $[34,35]$, nanoscale oxide particles will thus be formed. Annealing the powders at different temperatures is expected to produce Fe-14Cr-1.5Zr alloys with very different nano-oxide particle sizes and grain sizes. To prepare the samples for He irradiation, the annealed powders were further cold compressed into discs under $2.5 \mathrm{GPa}$ and mechanically polished with an Allied Mulitprep system. Fe-14Cr-2Hf alloy was synthesized in the same way using $99.6 \%$ purity Hf powder from Alfa Aesar, followed by a $700{ }^{\circ} \mathrm{C}$ annealing for 1 hour. The $\mathrm{Fe}-14 \mathrm{Cr}$ base alloys were also produced for comparison. The as-milled $\mathrm{Fe}-14 \mathrm{Cr}$ 
powders were subsequently annealed at $900{ }^{\circ} \mathrm{C}$ for 1 hour, $500{ }^{\circ} \mathrm{C}$ for 1 hour, and $500{ }^{\circ} \mathrm{C}$ for 26 hours. This produced the as-annealed $\mathrm{Fe}-14 \mathrm{Cr}$ alloy samples with very different grain sizes.

In this paper, we use the nomenclature of "A_B" to name all six alloy samples. Here, "A" refers to the alloy composition. "B" refers to the annealing temperature and time. Therefore, sample Fe14Cr2Hf_700C1h represents the Fe-14Cr-2Hf alloy annealed at $700{ }^{\circ} \mathrm{C}$ for $1 \mathrm{~h}$. Similarly, the Fe-14Cr-1.5Zr alloy annealed at $800{ }^{\circ} \mathrm{C}$ for $1 \mathrm{~h}$ and $900{ }^{\circ} \mathrm{C}$ for $1 \mathrm{~h}$ are designated as $\mathrm{Fe} 14 \mathrm{Cr} 1.5 \mathrm{Zr} \_800 \mathrm{C} 1 \mathrm{~h}$ and $\mathrm{Fe} 14 \mathrm{Cr} 1.5 \mathrm{Zr} \_900 \mathrm{C} 1 \mathrm{~h}$, respectively. The $\mathrm{Fe}-14 \mathrm{Cr}$ base alloys annealed at $500{ }^{\circ} \mathrm{C}$ for 1 or 26 hours and $900{ }^{\circ} \mathrm{C}$ for 1 hour are designated as $\mathrm{Fe} 14 \mathrm{Cr} \_500 \mathrm{C} 1 \mathrm{~h}, \mathrm{Fe} 14 \mathrm{Cr}$ 500C26h, and Fe14Cr_900C1h thereafter.

\subsection{Irradiation conditions}

Ion irradiations were performed at the Ion Beam Materials Laboratory at Los Alamos National Laboratory, using a Danfysik High Current Research Ion Implanter operating at $200 \mathrm{kV}$. Samples were irradiated with $200 \mathrm{keV} \mathrm{He}$ ions perpendicular to the sample surface to a fluence of $6.5 \times 10^{20}$ ions $/ \mathrm{m}^{2}$ and a flux of $2.2 \times 10^{17}$ ions $/ \mathrm{m}^{2} \bullet \mathrm{s}$. The temperature of the specimen during irradiation was maintained at $500{ }^{\circ} \mathrm{C}$ under pressure of $8 \times 10^{-5} \mathrm{~Pa}$. The estimated damage profile and He ion concentration in the Fe-14Cr alloy were simulated using the SRIM (Stopping and Range of Ions in Matter) program[36]. The simulation was performed using the detailed calculation mode with 
full damage cascades using a damage displacement threshold energy value of $40 \mathrm{eV}$ for both $\mathrm{Fe}$ and $\mathrm{Cr}$. The peak irradiation damage is about $5 \mathrm{dpa}$ at the depth of about $500 \mathrm{~nm}$. The peak He concentration is about 4 at.\% at a depth of about $550 \mathrm{~nm}$. A slight grain growth was observed in the Fe-14Cr-1.5Zr alloy samples after He ion irradiation at $500{ }^{\circ} \mathrm{C}$ for 50 minutes.

\subsection{TEM sample preparation}

Scanning/transmission electron microscopy (S/TEM) samples were prepared using the focused ion beam (FIB) 'lift-out' technique in an FEI Quanta 3D FEG dual-beam instrument. To protect the specimen top surface from $\mathrm{Ga}^{+}$ion sputtering/damage, the specimen was coated with $200 \mathrm{~nm}$ Pt using electron beam deposition followed by 3 $\mu \mathrm{m}$ Pt deposited using $\mathrm{Ga}^{+}$ion beam. Note that the thick Pt layer is deposited on the top surface of specimen to help prevent the specimen from bending in the final FIB thinning and polishing procedure. The FIB specimen was cut using $30 \mathrm{keV} \mathrm{Ga}^{+}$ions, followed by final thinning and polishing at $5 \mathrm{keV}$ and $2 \mathrm{keV}$.

\subsection{TEM/STEM techniques}

Conventional and high-resolution TEM images were taken in a JEM-2010F microscope operated at $200 \mathrm{kV}$. The HRTEM was done in the defocus condition for the values of $-512 \mathrm{~nm}$ at $80 \mathrm{kX}$ magnification, $-256 \mathrm{~nm}$ at $200 \mathrm{kX}$ magnification, and $-192 \mathrm{~nm}$ at $300 \mathrm{kX}$ magnification depending on the field of view and size of $\mathrm{He}$ bubbles. The characterization of the He bubble size and distribution is based on a 
series of HRTEM images acquired located along the irradiated depth. The statistical analysis of void swelling, bubble size and density along the depth from the top surface inward was performed on 750-1500 bubbles using a self-developed program. With the publication of this paper, the code is available upon request.

HAADF-STEM images were taken in an aberration-corrected FEI Titan G2 microscope operated at $200 \mathrm{kV}$. The probe size, convergence angle and collection inner semi-angle were $0.1 \mathrm{~nm}, 21 \mathrm{mrad}$ and $77 \mathrm{mrad}$, respectively. EDS elemental mapping was acquired using the a Titan G2 microscope equipped with four quadrant windowless silicon drift detectors (SDDs) with a total X-ray collection angle of $0.7 \mathrm{sr}$. The probe current was about $100 \mathrm{pA}$. The utilization of large-area detectors in the Titan improves the signal/background ratio of EDS mapping and allows the low level solute to be detected. In addition, EELS elemental mapping was acquired using a Gatan Enfinium ER spectrometer equipped Titan microscope. This helps distinguish $\mathrm{Cr}$ and $\mathrm{O}$ element distribution at nanometer scale. The EELS collection angle is about $39 \mathrm{mrad}$.

\section{Results and Discussion}

\subsection{Nano-oxide particles}

He bubbles are observed near nano-sized $\mathrm{ZrO}_{2}$ particles in the $\mathrm{Fe} 14 \mathrm{Cr} 1.5 \mathrm{Zr} \_900 \mathrm{C} 1 \mathrm{~h}$ sample after He irradiation. Fig. 1a shows the HRTEM images with relatively small He bubble concentration and damage concentration at the depth of 350-400 nm below 
the surface. Nano-size particles with lattice fringes are found in the ferritic matrix, as pointed out by yellow triangles. These nano-sized particles were identified as $\mathrm{ZrO}_{2}$ in our previous study [34]. Interestingly, He bubbles are formed at the boundaries of these oxide particles, as indicated by the green triangles. The He bubbles are mostly spherical or near-spherical in shape with diameters less than $5 \mathrm{~nm}$. In the region where He concentration and damage are largest, at the depth 550-600 nm, a high density of nano $\mathrm{ZrO}_{2}$ particles are still observed, as shown in Fig. 1b, indicating good stability of nano $\mathrm{ZrO}_{2}$ particles subject to $200 \mathrm{keV}$ He irradiation. One or more $\mathrm{He}$ bubbles can be seen near the oxide particles, showing the strong He trapping effect by nano $\mathrm{ZrO}_{2}$ particles. It is noteworthy to point out that there are some He bubbles that are irregular in shape, with a strong tendency to aggregate at the nano oxide particle boundaries.

Figure 2 shows EDS mapping collected from both the non-irradiated region and a heavily irradiated region in the Fe14Cr1.5Zr_800C1h sample. The annealing of Fe14Cr1.5Zr_800C1h sample produced a smaller nano-oxide size (2.6 $\mathrm{nm}$ in average) than that of Fe14Cr1.5Zr_900C1h $(4.8 \mathrm{~nm})$. Consistent with the observations in Fig. 1, high-density $\mathrm{ZrO}_{2}$ nano particles can be still observed in the heavily irradiated region in Fig. 2b, indicating their radiation tolerance. Similarly, the He bubbles formed in this region are typically located near the $\mathrm{ZrO}_{2}$ particles, suggesting a strong $\mathrm{He}$ trapping affinity by $\mathrm{ZrO}_{2}$ nano particles. $\mathrm{Cr}$ segregation at grain boundaries is also seen in the materials microstructure. This $\mathrm{Cr}$ segregation is detected in both the non-irradiated region and the irradiated region, as indicated by white triangles. 
In the $\mathrm{Fe}-14 \mathrm{Cr}-2 \mathrm{Hf}$ alloy annealed at $700{ }^{\circ} \mathrm{C}$ for 1 hour, nano oxide particles are also observed in the microstructure. Fig. 3 shows the HAADF-STEM images obtained from the non-irradiated and the heavily irradiated regions in the Fe14Cr2Hf_700C1h sample. These particles present in this material were identified as $\mathrm{HfO}_{2}$ in our previous studies[35], and appear as bright dots uniformly dispersed in the microstructure shown in Fig. 3a. The $\mathrm{HfO}_{2}$ particles are only in the range of $0.5-4 \mathrm{~nm}$ with an average size of around $1.9 \mathrm{~nm}$. Due to the large $\mathrm{Z}$ number of $\mathrm{Hf}$, these nano oxide particles can be easily detected by the bright contrast in HAADF-STEM. It is noteworthy to point out that the Fe14Cr2Hf_700C1h sample produces the smallest void swelling percentage among all the $\mathrm{Fe}-14 \mathrm{Cr}$ alloy samples investigated in this study. Unlike the $\mathrm{ZrO}_{2}$ particles in the previously discussed sample, He bubbles (shown as dark dots) and nano $\mathrm{HfO}_{2}$ particles evolve into core-shell structures shown in Fig. 3b, with nano oxide particles forming shell structures around He bubbles. This morphology suggests the formation of shell-shaped $\mathrm{HfO}_{2}$ after the formation of the $\mathrm{He}$ bubble, as pointed out by the arrow in Fig. 3b. Such structure is most likely formed via the surface diffusion of $\mathrm{Hf} / \mathrm{O}$ from the pre-existing $\mathrm{HfO}_{2}$ particle under irradiation. As most $\mathrm{He}$ bubbles are found to have such a core-shell structure, this could potentially suppress the growth of He bubbles and thus reduce the void swelling. In addition to the oxides, hafnium carbide is also found in the microstructure with much brighter contrast and a size range of about 10-20 $\mathrm{nm}$ [35]. It can be seen in Fig. $3 \mathrm{~b}$ that HfC with bright contrast appears to be smaller and irregular in shape as compared 
with HfC in Fig. 3a. This indicates that Hf carbide is unstable and tends to dissolve in the ferritic matrix during He irradiation.

Our observations show a close relationship between nano oxides and He bubble evolution, indicating that these nano-size $\mathrm{ZrO}_{2}$ or $\mathrm{HfO}_{2}$ particles are effective sites for He bubble formation. This effect is similar to that of nano Y-Ti-enriched oxide particles, whose interface is found to be an effective trap for helium [17, 28, 31, 32]. A direct observation of He trapping at nano-size Y-Ti-enriched oxide particles can be seen in other reports $[17,31]$. However, it is still unclear whether other oxides could also trap $\mathrm{He}$ at their interfaces. The strong He trapping ability at Y-Ti-enriched oxide nano particles appears to originate from the interaction between helium and neighboring oxygen atoms on the interface, as revealed from the first-principle calculation of $\mathrm{Y}_{2} \mathrm{Ti}_{2} \mathrm{O}_{7}$ [33]. It is possible that a similar He oxygen interaction could also occur at the interface in other types of oxides such as $\mathrm{ZrO}_{2}$ and $\mathrm{HfO}_{2}$. The current observations therefore suggest other possible nano-oxide candidates for $\mathrm{He}$ entrapment.

Nano oxide particles are not only found in $\mathrm{Fe}-14 \mathrm{Cr}$ alloys with $\mathrm{Zr}$ or Hf additions, but also seen in Fe-14Cr base alloys. In the Fe14Cr_500C26h sample, for example, a high-density of nano particles appear as dark spots in the HAADF-STEM image in Fig. 4a. The composition map obtained using electron energy loss spectroscopy (EELS) reveals that these particles are $\mathrm{Cr}$ and $\mathrm{O}$ enriched, while $\mathrm{Fe}$ is depleted. This 
suggests the formation of nano Cr-enriched oxide particles upon annealing, similar to $\mathrm{ZrO}_{2}$ and $\mathrm{HfO}_{2}$ in $\mathrm{Fe}-14 \mathrm{Cr}$ alloys with $\mathrm{Zr}$ and $\mathrm{Hf}$ additions[34, 35]. Chromium oxide particles are also found in the Fe14Cr_500C1h and Fe14Cr_900C1h samples. The average size of these nano particles varies with the annealing temperature and time. Specifically, the Fe14Cr_500C1h and Fe14Cr_500C26h samples contain relatively small oxide particles with average size of around $2.3 \mathrm{~nm}$ and $3.4 \mathrm{~nm}$, respectively, while the Fe14Cr_900C1h sample annealed at $900{ }^{\circ} \mathrm{C}$ has a much larger average oxide particle size of around $21.1 \mathrm{~nm}$. Note that the large oxide particles formed in the Fe14Cr_900C1h sample are typically separated by large distances on the order of 100 nm. The Fe14Cr_900C1h sample can be regarded as a coarse grain counterpart, whereas the distance between He bubbles is much smaller $(<10 \mathrm{~nm})$ than that between oxide particles. Due to the different Zener pinning effects from these different size scales of nano particles [37], the variation of grain size among $\mathrm{Fe}-14 \mathrm{Cr}$ alloys upon annealing would also be different. The grain size of these Fe-14Cr base alloys was statically analyzed and is shown in Fig. 5.

The formation of oxide particles in all the $\mathrm{Fe}-14 \mathrm{Cr}$ alloy samples in this investigation is closely related to the ball milling process. As the materials exposed to severe deformation during ball milling, a high density of vacancies was created in the matrix. Calculations show that these vacancies have a large bonding energy when forming oxygen-vacancy pairs, which helps stabilize oxygen in the matrix [38]. Consequently, the presence of excess oxygen from surface oxidation or oxygen in the starting 
powders can be mechanically dissolved in the alloys during milling. This is fundamentally similar to the mechanical alloying process in producing ODS alloys $[30,39]$. The oxygen in the latter is incorporated from the addition of $\mathrm{Y}_{2} \mathrm{O}_{3}$ oxide of about 0.2-0.3 wt.\% during ball milling [3, 30]. The subsequent annealing of as-milled samples allows further diffusion and reaction of oxygen with $\mathrm{Zr}$ and $\mathrm{Hf}$ atoms. The Gibbs free energy change for oxidation is about $-1183 \sim-1201 \mathrm{kJmol}^{-1}$, and $-1242 \sim$ $-1263 \mathrm{kJmol}^{-1}$ in the temperature range of about $500-900^{\circ} \mathrm{C}$, respectively [40]. Even without the additions of $\mathrm{Zr} / \mathrm{Hf}$, other elements such as $\mathrm{Cr}$ can also form oxides in the microstructure. Although the Gibbs free energy of $\mathrm{Cr}_{2} \mathrm{O}_{3}$ is $-613 \sim-547 \mathrm{kJmol}^{-1}$ in the annealing temperature from $500{ }^{\circ} \mathrm{C}$ to $900{ }^{\circ} \mathrm{C}$, this is still larger than that of $\mathrm{Fe}_{3} \mathrm{O}_{4}$ $\left(-432 \sim 371 \mathrm{kJmol}^{-1}\right)$ [41]. The formation of $\mathrm{Cr}$ oxide is therefore expected to be more favorable than Fe oxide formation in the microstructure.

\subsection{Nano-oxide size effect}

As the dependence of nano-sized oxide particles and $\mathrm{He}$ bubbles is commonly observed, a systematic study on the size effect of nano oxides was conducted for the six Fe-14Cr alloy samples. The microstructure of the six Fe-14Cr samples subject to $200 \mathrm{keV} \mathrm{He}$ irradiation at $500{ }^{\circ} \mathrm{C}$ is shown by cross-sectional TEM images in Fig. 6(a1-f1). For all Fe-14Cr alloy samples, their microstructures typically contain $\mathrm{He}$ bubbles at a depth of about 150-700 $\mathrm{nm}$. The damage and He ion concentration profile calculated using SRIM taken along the depth direction and are shown in Fig. 6(f1). Along this direction the bubble size and density are found to be correlated to the $\mathrm{He}$ 
concentration profile from SRIM calculations. The largest bubble size and density occurs at the maximum He concentration region, at a depth of around $550 \mathrm{~nm}$.

Despite the general trend of the He bubble distribution, the bubble size and bubble density among all Fe-14Cr alloy samples, there appears to be different behavior under the same irradiation condition within the different samples. This can be seen from Fig. 6 (a2-f2) where HRTEM images are taken from the region at peak He concentration, at about $550 \mathrm{~nm}$ in depth. Small and near spherical shaped He bubbles are seen in Fig. $6(a 2, b 2, c 2, d 2)$, while large and near spherical shaped He bubbles are seen in Fig. 6 (e2). Interestingly, in Fe14Cr_900C1h sample large and faceted He bubbles are seen in Fig. 6 (f2) bounded by certain low energy planes. As discussed in the earlier section, the Fe14Cr_900C1h sample can be regarded as a coarse grain sample, with weak effect from oxide particles. The change of bubble shape suggests a strong role of nano-oxides in controlling the evolution of He bubble shape. For each sample, the corresponding selected area diffraction patterns can be seen in Fig. 6 (a3-f3).

We list the materials based on the average size of the oxide particles in Fig. 7 (same sequence is used in Fig. 5 and 6). The corresponding histograms showing the average bubble size, bubble density and swelling percentage are presented in Fig. 8 to quantify the existing He bubbles along the depth profile direction. Note that the vertical scales are different for different alloys and conditions. Over 700-1500 bubbles were statistically analyzed from a series of HRTEM images along the specimen depth. These histograms are consistent with the He concentration profile in Fig. 6 (f1). The 
average size of He bubbles gradually increases along the depth, reaching its maximum size at the depth of 500-600 $\mathrm{nm}$, and then decreases at larger depth. The bubble density follows a similar trend and reaches its maximum density at around 500-600 $\mathrm{nm}$. The bubble density values in this study are in the range of about $10^{23}-10^{24} \mathrm{~m}^{-3}$, which is comparable to that reported for nanostructured ODS ferritic alloys subject to He irradiation $[3,17,20]$.

The void swelling percentage can be estimated from the total volume of He bubbles in a reference area of a certain depth range, which can be used as an indicator of irradiation damage tolerance of these alloys to He irradiation (Fig. 8). The effective thickness at the reference area can be estimated from EELS. The general profile of void swelling is found to track closely with the He concentration profile as shown in Fig. 6 (f1).

Fig. 9 lists the peak values of the average He bubble size, He bubble density, and swelling percentage from Fig. 8 to provide a direct comparison of the relative radiation resistant properties of all six Fe-14Cr alloy samples. The Fe14Cr_900C1h and Fe14Cr1.5Zr_900C1h samples in Fig. 9c show the largest void swelling percentage. They contain both the highest average He bubble sizes and the smallest average bubble number density, as shown in Fig. 9a and 9b. In contrast, the Fe14Cr2Hf_700C1h and Fe14Cr_500C1h samples show void swelling percentage as small as $0.95 \%$ and $1.0 \%$ in Fig. 9c, indicating an enhancement of irradiation 
resistance. As shown in Fig. 9a and 9b, the Fe14Cr2Hf_700C1h sample contains the smallest average bubble size $(2.2 \mathrm{~nm})$ and the highest bubble number density $\left(1.5 \times 10^{24} \mathrm{~m}^{-3}\right)$. The Fe14Cr_500C1h sample also contains small bubbles $(2.8 \mathrm{~nm})$ but with smaller bubble density of about $7.3 \times 10^{23} \mathrm{~m}^{-3}$. These results are anticipated from the HRTEM images taken at the peak He concentration region in Fig. 6 (a2 and b2). Both bubble size and bubble density would be related the materials radiation resistance, but it is the total volume of the He bubbles that plays the major role for swelling resistance.

If we use the swelling percentage at peak He concentration to represent the materials radiation resistance to swelling at the extreme condition, it is found to have a correlation with the average particle size of the oxide particles. In particular, the void swelling percentage appears to be proportional to the particle size as shown in Fig. 9d. As the oxide particle size decreases, the value of the swelling percentage drops. The size of nano-oxide particles is also found to play a significant role in controlling the void swelling percentage, especially when the nano-oxide particle size is sufficiently small. According to the current observation in Fig. 9d, the effective oxide size should be less than $3.5-4 \mathrm{~nm}$. The change of swelling percentage is found to be sensitive to the change of oxide particle size below an effective size. As can be seen from the Fig. 9d, a slight decrease of the oxide nano-particle size of about $1 \mathrm{~nm}$ results in over $30 \%$ reduction of the swelling percentage. Although $\mathrm{Zr}$, Hf, or $\mathrm{Cr}$ oxides in the current study are very different from that of $\mathrm{Y}-\mathrm{Ti}$ enriched oxides in conventional 
nanostructured ODS alloys, the observed effective size range is similar to the typical size range of Y-Ti enriched oxides for nanostructured ferritic ODS alloys with enhanced irradiation resistance $[4,10,25,26]$. This strongly suggests that our current observations in $\mathrm{Fe}$ based alloys with $\mathrm{Zr}$, $\mathrm{Hf}$, or $\mathrm{Cr}$ oxides could provide a useful reference to other oxide candidates that might have similar effect on enhanced irradiation resistance in ferritic alloys.

\subsection{Grain size effect}

Fig. 9d also shows that the grain size significantly affects radiation resistance to swelling, as demonstrated by the $\mathrm{Fe} 14 \mathrm{Cr} \_500 \mathrm{C} 1 \mathrm{~h}$ sample. This sample has the smallest grain size $(17 \mathrm{~nm})$ among all six alloy samples, its void swelling percentage drops below the dash trend line connecting sample Fe14Cr2Hf_700C1h and sample Fe14Cr1.5Zr_800C1h. Its swelling percentage is almost comparable to that of the Fe14Cr2Hf_700C1h sample, despite its relatively large oxide size. Smaller grains contain a large fraction of grain boundary areas per unit volume, which promotes the recombination of the vacancy and interstitial and thus enhances the radiation resistance in varies nanocrystalline materials[42]. This observation supports the positive effect of nanocrystalline grain sizes in reducing the He bubble formation. A strong grain size effect can only be clearly seen when the average grain size becomes sufficiently small. The effect of grain size on void swelling can be attributed to the reduction of bubble density in the microstructure. This behavior can be seen in the Fe14Cr_500C26h, Fe14Cr1.5Zr_800C1h and Fe14Cr_500C1h samples shown in Fig. 
9; as the grain size drops, the bubble density drops. The bubble size, however, does not significantly change with the grain size among these alloy samples.

It is known that He bubbles can nucleate on defects in a ferritic matrix, such as oxide-interfaces, grain boundaries and dislocations. When the grain size is refined to the nanocrystalline regime, there is a noticeable drop of dislocation density in grains smaller than $75 \mathrm{~nm}$, as reported in work by Cheng et al [43]. Such effects may cause the reduction of potential nucleation sites of He bubbles formed on dislocations[43]. Although Fe14Cr2Hf_700C1h and Fe14Cr1.5Zr_800C1h and Fe14Cr_500C26h samples have similar grain size, their void swelling percentage is very different, and is essentially determined by their nano-oxide sizes.

\section{Conclusion}

We have studied the effect of different nano oxide particles on the resistance of $\mathrm{He}$ irradiation in $\mathrm{Fe}-14 \mathrm{Cr}$ base alloys. High densities of nano-size $\mathrm{ZrO}_{2}$ particles are found in the ferritic matrix with one or more He bubbles existing near-by, showing a strong He trapping effect by nano $\mathrm{ZrO}_{2}$ particles coupled with good stability of nano $\mathrm{ZrO}_{2}$ particles when subjected to $200 \mathrm{keV} \mathrm{He}$ irradiation. He bubbles and nano $\mathrm{HfO}_{2}$ particles evolve into core-shell structures and thus reduce void swelling by suppressing the growth of He bubbles. Chromium oxide particles are also found in Fe-14Cr based alloys. 
The average He bubble size, He bubble density, and swelling percentage are shown in histograms with similar profiles along the depth as the He concentration profile obtained from SRIM calculations. With decreasing oxide particle size, swelling percentage drops, and the effective oxide particle size is smaller than $3.5-4 \mathrm{~nm}$. A slight decrement of nano oxide particle size of about $1 \mathrm{~nm}$ was shown to result in over $30 \%$ reduction of the swelling percentage. Such size effect of nano-oxide particles is found to play a significant role in controlling the void swelling percentage in the studied $\mathrm{Fe}-14 \mathrm{Cr}$ alloys subject to $200 \mathrm{keV} \mathrm{He}$ irradiation at $500{ }^{\circ} \mathrm{C}$, which may also help design ODS alloys including other oxide candidates. Grain size effect on the radiation resistance is also observed only when the average grain size becomes sufficiently small.

\section{Acknowledgements}

We acknowledge financial support from the Department of Energy Idaho Field Office (DE-NE0000538) and from the LDRD program \# 20130118DR in Los Alamos National Laboratory. The authors also acknowledge the use of the Analytical Instrumentation Facility (AIF) at North Carolina State University, which is supported by the State of North Carolina and the National Science Foundation. Lastly, the authors also acknowledge Yongqiang Wang and Juan Wen from the Ion Beam Materials Laboratory at Los Alamos National Laboratory for performing the irradiations on the samples used in this study. 


\section{References}

[1] S. Ukai, M. Fujiwara, Journal of Nuclear Materials, 307 (2002) 749-757.

[2] R.L. Klueh, A.T. Nelson, Journal of Nuclear Materials, 371 (2007) 37-52.

[3] G.R. Odette, M.J. Alinger, B.D. Wirth, Annual Review of Materials Research, 38 (2008) 471-503.

[4] A. Hirata, T. Fujita, Y.R. Wen, J.H. Schneibel, C.T. Liu, M.W. Chen, Nature Mater., 10 (2011) 922-926.

[5] T. Hayashi, P.M. Sarosi, J.H. Schneibel, M.J. Mills, Acta Materialia, 56 (2008) 1407-1416.

[6] C. Sun, S. Zheng, C.C. Wei, Y. Wu, L. Shao, Y. Yang, K.T. Hartwig, S.A. Maloy, S.J. Zinkle, T.R. Allen, H. Wang, X. Zhang, Sci. Rep., 5 (2015).

[7] B. Mazumder, M.E. Bannister, F.W. Meyer, M.K. Miller, C.M. Parish, P.D. Edmondson, Nuclear Materials and Energy, 1 (2015) 8-12.

[8] C. Lu, Z. Lu, R. Xie, C. Liu, L. Wang, Journal of Nuclear Materials, 455 (2014) 366-370.

[9] C.M. Parish, R.M. White, J.M. LeBeau, M.K. Miller, Journal of Nuclear Materials, 445 (2014) 251-260.

[10] H. Zhang, C. Zhang, Y. Yang, Y. Meng, J. Jang, A. Kimura, Journal of Nuclear Materials, 455 (2014) 349-353.

[11] H. Trinkaus, B.N. Singh, Journal of Nuclear Materials, 323 (2003) 229-242.

[12] X.M. Bai, A.F. Voter, R.G. Hoagland, M. Nastasi, B.P. Uberuaga, Science, 327 (2010) 1631-1634.

[13] Y. Zhang, H. Huang, P.C. Millett, M. Tonks, D. Wolf, S.R. Phillpot, Journal of Nuclear Materials, 422 (2012) 69-76.

[14] C. Di, J. Wang, T. Chen, L. Shao, Science Report, 3 (2013) 1450.

[15] K.Y. Yu, Y. Liu, C. Sun, H. Wang, L. Shao, E.G. Fu, X. Zhang, Journal of Nuclear Materials, 425 (2012) 140-146.

[16] P. Trocellier, S. Agarwal, S. Miro, Journal of Nuclear Materials, 445 (2014) 128-142.

[17] G.R. Odette, P. Miao, D.J. Edwards, T. Yamamoto, R.J. Kurtz, H. Tanigawa, Journal of Nuclear Materials, 417 (2011) 1001-1004.

[18] L. Fave, M.A. Pouchon, M. Döbeli, M. Schulte-Borchers, A. Kimura, Journal of Nuclear Materials, 445 (2014) 235-240.

[19] X. Wang, A.M. Monterrosa, F. Zhang, H. Huang, Q. Yan, Z. Jiao, G.S. Was, L. Wang, Journal of Nuclear Materials, 462 (2015) 119-125.

[20] P.D. Edmondson, C.M. Parish, Y. Zhang, A. Hallén, M.K. Miller, Journal of Nuclear Materials, 434 (2013) 210-216.

[21] P.D. Edmondson, C.M. Parish, Q. Li, M.K. Miller, Journal of Nuclear Materials, 445 (2014) 84-90.

[22] A. Ramar, N. Baluc, R. Schäublin, Journal of Nuclear Materials, 386-388 (2009) 515-519.

[23] L. Hsiung, M. Fluss, S. Tumey, J. Kuntz, B. El-Dasher, M. Wall, B. Choi, A. Kimura, F. Willaime, Y. Serruys, Journal of Nuclear Materials, 409 (2011) 72-79.

[24] V. de Castro, T. Leguey, A. Muñoz, M.A. Monge, P. Fernández, A.M. Lancha, R. Pareja, Journal of Nuclear Materials, 367-370, Part A (2007) 196-201.

[25] M.K. Miller, K.F. Russell, D.T. Hoelzer, Journal of Nuclear Materials, 351 (2006) 261-268.

[26] H. Sakasegawa, L. Chaffron, F. Legendre, L. Boulanger, T. Cozzika, M. Brocq, Y. de Carlan, Journal of Nuclear Materials, 384 (2009) 115-118.

[27] D.T. Hoelzer, J. Bentley, M.A. Sokolov, M.K. Miller, G.R. Odette, M.J. Alinger, Journal of Nuclear Materials, 367-370, Part A (2007) 166-172.

[28] L.L. Hsiung, M.J. Fluss, S.J. Tumey, B.W. Choi, Y. Serruys, F. Willaime, A. Kimura, Physical Review B, 
82 (2010) 184103.

[29] V. Badjeck, M.G. Walls, L. Chaffron, J. Malaplate, K. March, Journal of Nuclear Materials, 456 (2015) 292-301.

[30] M.J. Alinger, G.R. Odette, D.T. Hoelzer, Acta Materialia, 57 (2009) 392-406.

[31] K. Yutani, H. Kishimoto, R. Kasada, A. Kimura, Journal of Nuclear Materials, 367-370, Part A (2007) 423-427.

[32] R. Kögler, W. Anwand, A. Richter, M. Butterling, X. Ou, A. Wagner, C.L. Chen, Journal of Nuclear Materials, 427 (2012) 133-139.

[33] T. Danielson, C. Hin, Journal of Nuclear Materials, 452 (2014) 189-196.

[34] W.Z. Xu, L.L. Li, M. Saber, C.C. Koch, Y.T. Zhu, R.O. Scattergood, Journal of Nuclear Materials, 452 (2014) 434-439.

[35] W. Xu, L. Li, M. Saber, C. Koch, Y. Zhu, R. Scattergood, Metall and Mat Trans A, (2015) 1-11.

[36] D.J. Ziegler, J.P. Biersack, M.D. Ziegler, The stopping and range of ions in matter, Lulu Press, Morrisville, 2008.

[37] P.A. Manohar, M. Ferry, T. Chandra, ISIJ International, 38 (1998) 913-924.

[38] C.L. Fu, M. Krčmar, G.S. Painter, X.-Q. Chen, Physical Review Letters, 99 (2007) 225502.

[39] W. Xu, L. Li, M. Saber, C.C. Koch, Y. Zhu, R.O. Scattergood, Journal of Nuclear Materials, 452 (2014) 434-439.

[40] M.C. Zeman, C.C. Fulton, G. Lucovsky, R.J. Nemanich, W.C. Yang, Journal of Applied Physics, 99 (2006) 023519.

[41] D.R. Gaskell, Introduction to the thermodynamics of materials (4th Edition), Taylor \& Francis, New York, 2003.

[42] X.-M. Bai, A.F. Voter, R.G. Hoagland, M. Nastasi, B.P. Uberuaga, Science, 327 (2010) 1631-1634.

[43] G.M. Cheng, W.W. Jian, W.Z. Xu, H. Yuan, P.C. Millett, Y.T. Zhu, Materials Research Letters, 1 (2012) 26-31. 


\section{Figures and legends}
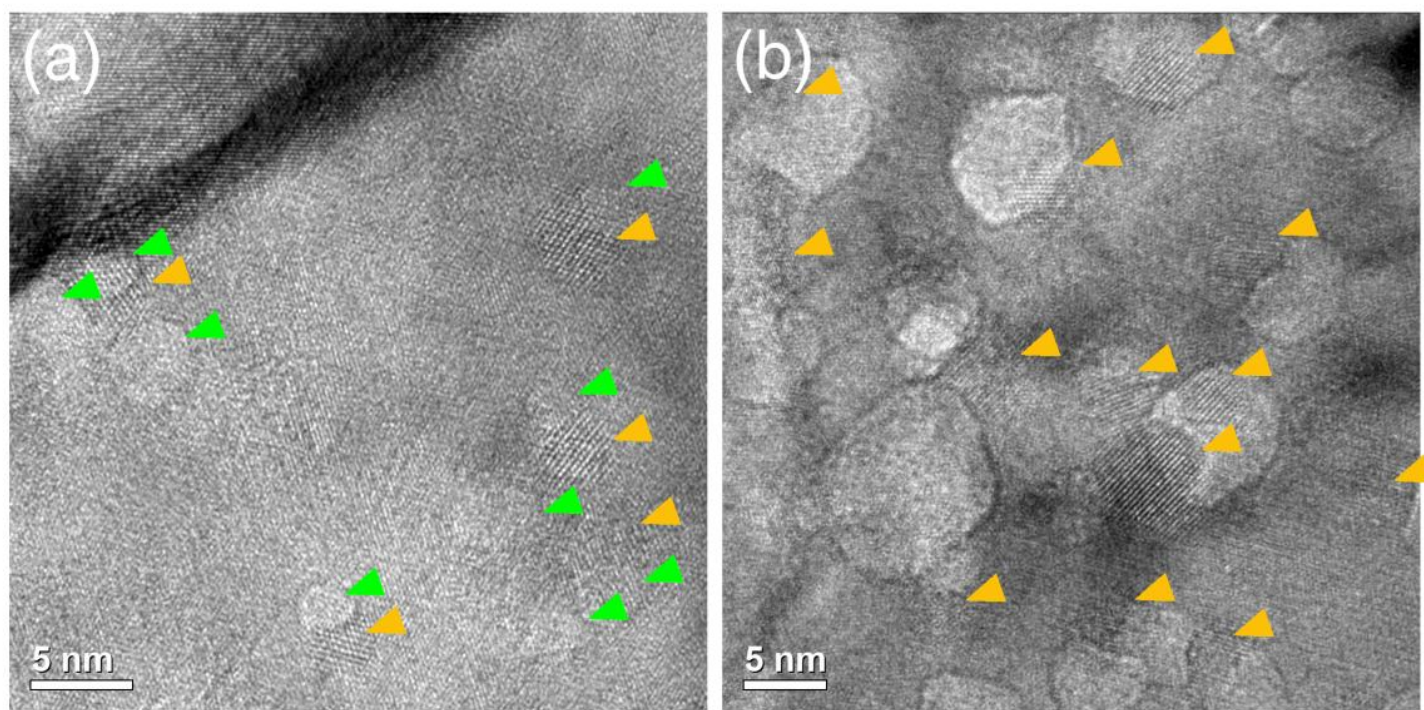

Fig. 1. HRTEM image of (a) He irradiated Fe14Cr1.5Zr_900C1h sample at depth of (a) 350-400nm and (b) 550-600nm from the top surface. Arrows show the He bubble formed at the vicinity of the nano-size $\mathrm{ZrO}_{2}$ particles.

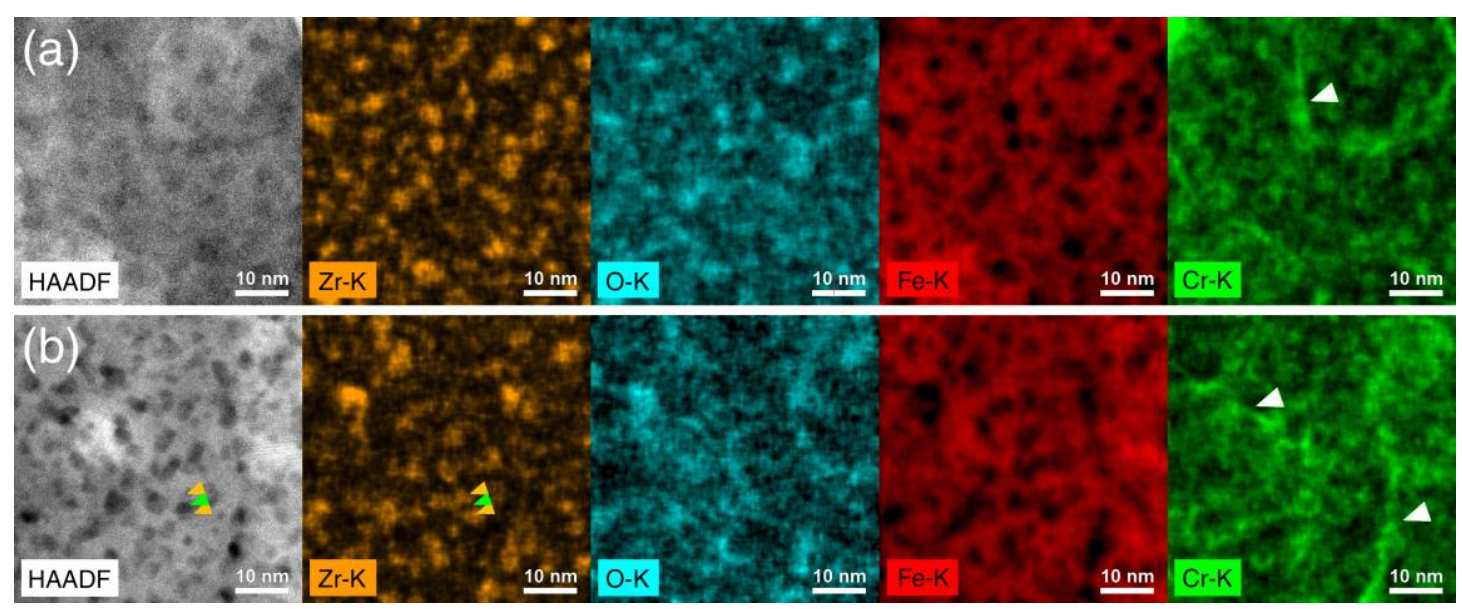

Fig. 2. The stability of $\mathrm{ZrO}_{2}$ particle in $\mathrm{Fe} 14 \mathrm{Cr} 1.5 \mathrm{Zr} \_800 \mathrm{C} 1 \mathrm{~h}$ sample subject to 200 $\mathrm{keV} \mathrm{He}{ }^{+}$irradiation with total fluence of $6.5 \times 10^{20}$ ions $/ \mathrm{m}^{2}$ at 500C. HAADF-STEM image and elemental mapping of $\mathrm{Zr}-\mathrm{K}, \mathrm{O}-\mathrm{K}, \mathrm{Fe}-\mathrm{K}$ and $\mathrm{Cr}-\mathrm{K}$ in (a) a non-irradiated area and (b) an irradiated area close to the 550-600 nm depth region. Cr segregation is both seen in the non-irradiated and the irradiated area, as marked by the white arrows. 

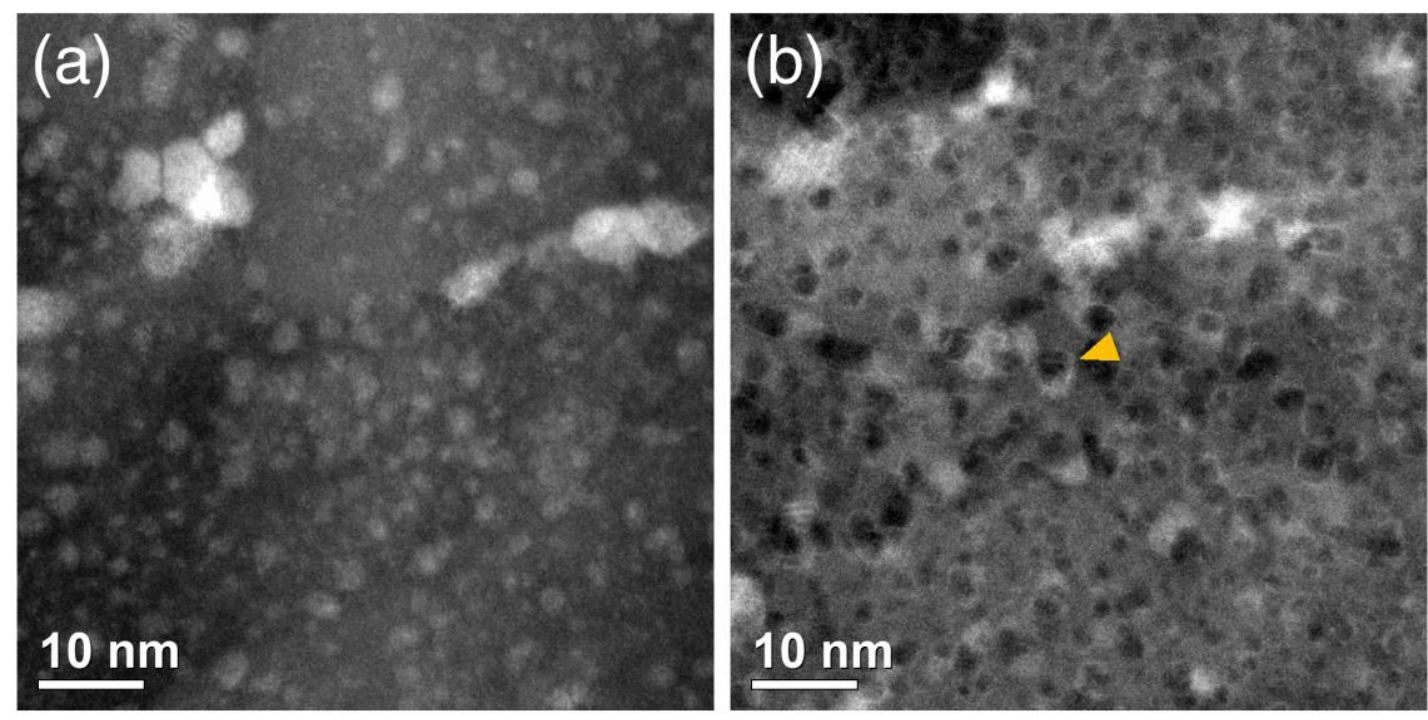

Fig. 3. The change of $\mathrm{HfO}_{2}$ particle in $\mathrm{Fe} 14 \mathrm{Cr} 2 \mathrm{Hf}$-700C1h sample subject to $200 \mathrm{keV}$ $\mathrm{He}^{+}$irradiation with total fluence of $6.5 \times 10^{20}$ ions $/ \mathrm{m}^{2}$ at $500{ }^{\circ} \mathrm{C}$. HAADF-STEM image in (a) non-irradiated area and (b) irradiated area at the depth of 550-600 nm. As marked by the yellows arrow, the morphology of $\mathrm{HfO}_{2}$ particle evolves to a shell structure around the He bubble.
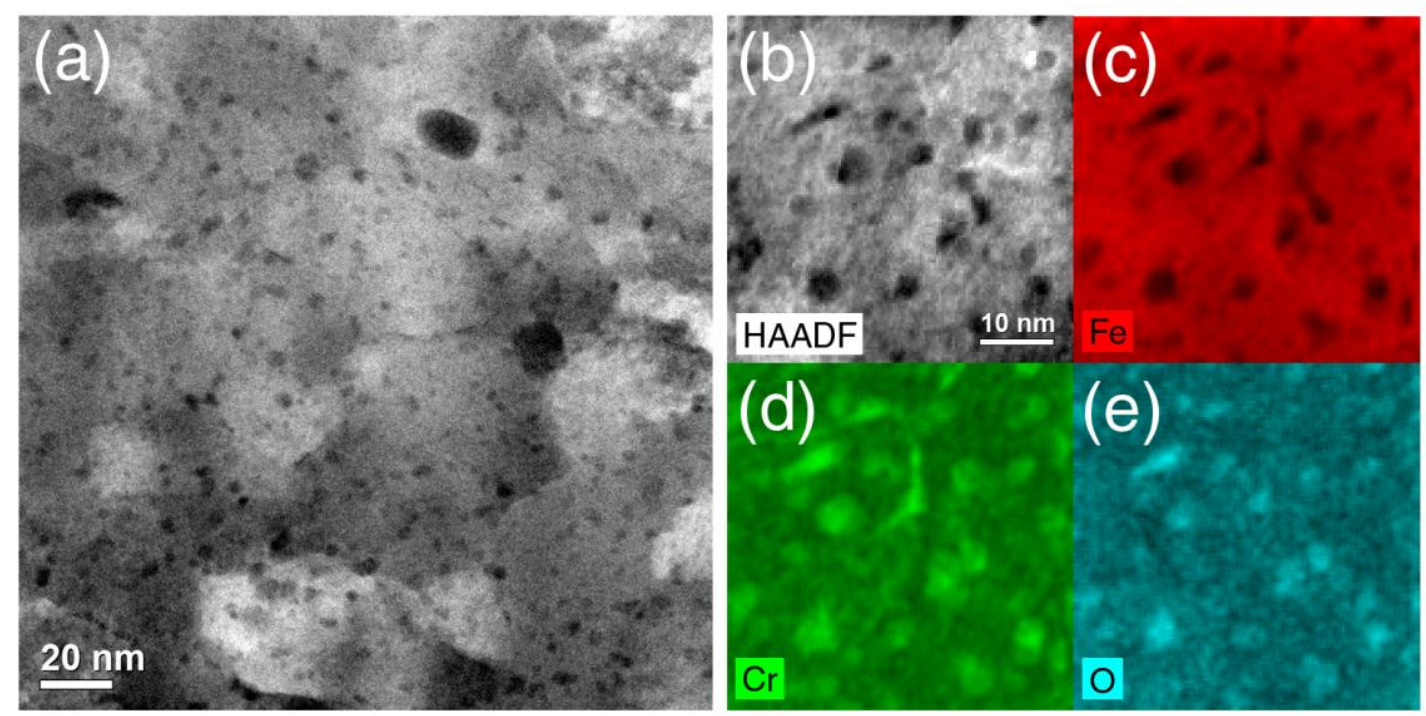

Fig. 4. Electron energy loss spectroscopy (EELS) elemental mapping and high resolution HAADF-STEM images of the chromium oxide in Fe14Cr_500C26h sample. (a) Microstructure overview shows high density chromium oxide dispersed in microstructure. (b) HAADF-STEM image and (c-e) EELS elemental mapping (Fe-L, $\mathrm{Cr}-\mathrm{L}, \mathrm{O}-\mathrm{K})$ of the chromium oxide phase in ferritic matrix. 

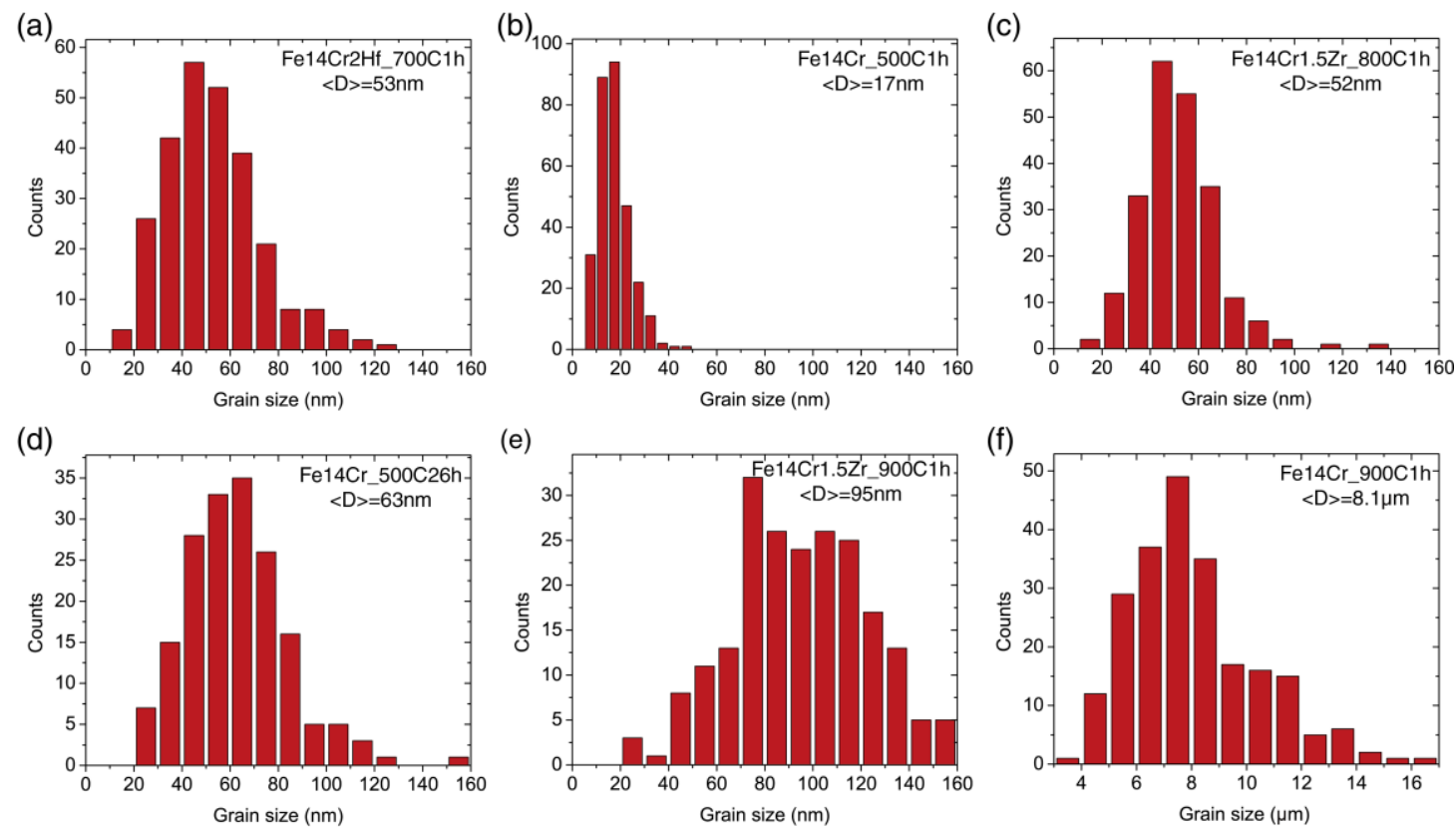

Fig. 5. Grain size histogram of (a) Fe14Cr2Hf_700C1h, (b) Fe14Cr_800C1h, (c)

$\mathrm{Fe} 14 \mathrm{Cr} 1.5 \mathrm{Zr} \_800 \mathrm{C} 1 \mathrm{~h}, \quad$ (d) Fe14Cr_500C26h, (e) Fe14Cr1.5Zr_900C1h, (f) Fe14Cr_900C1h samples. 


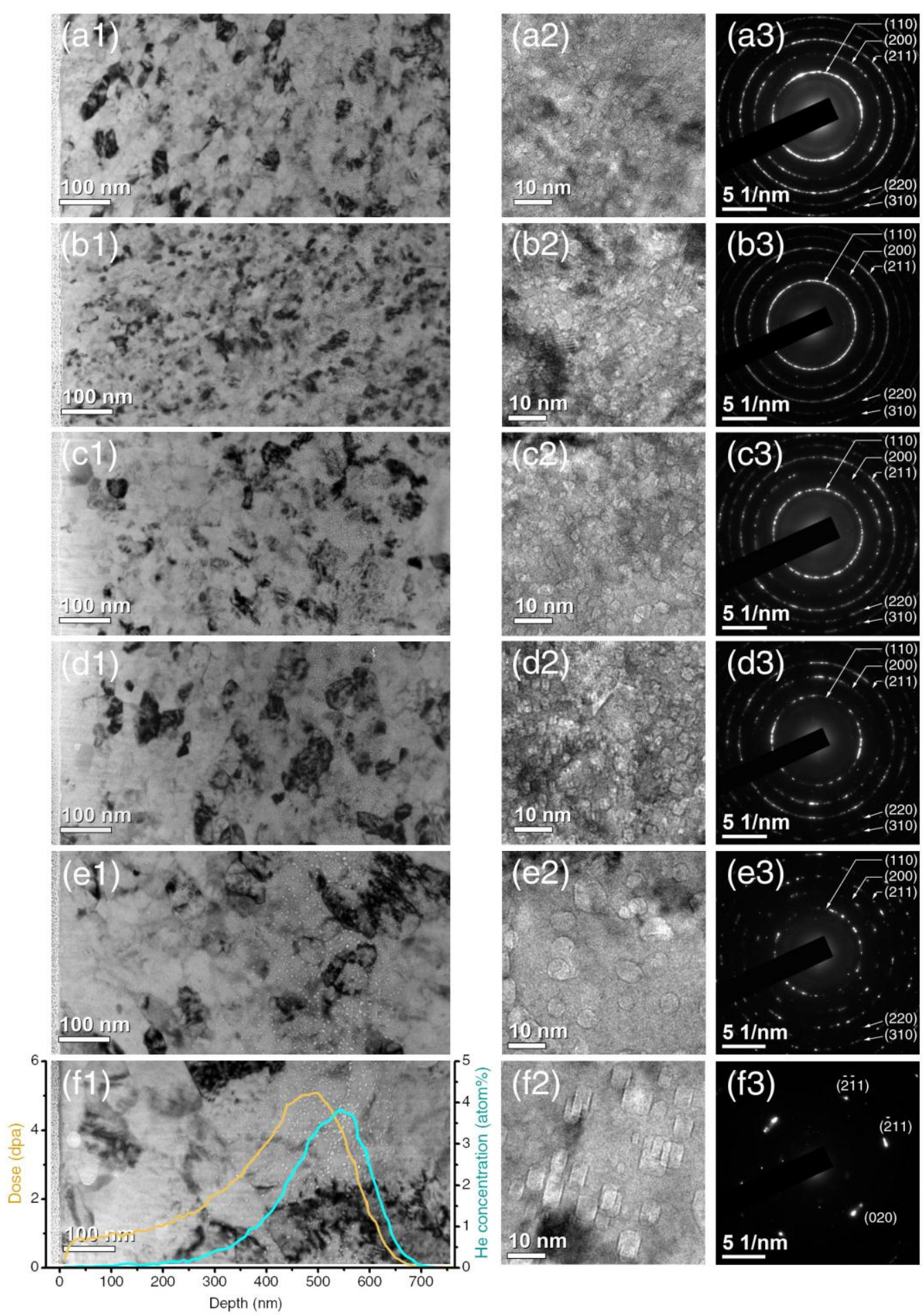

Fig. 6. Microstructure of $\mathrm{Fe}-14 \mathrm{Cr}$ alloy samples subject to $200 \mathrm{keV}$ He irradiation with total fluence of $6.5 \times 10^{20}$ ions $/ \mathrm{m}^{2}$ at $500{ }^{\circ} \mathrm{C}$. (a1-f1) Cross-section TEM image showing the depth profile of $\mathrm{He}$ bubble distribution in $\mathrm{Fe} 14 \mathrm{Cr} 2 \mathrm{Hf}$-700C1h, Fe14Cr_500C1h, Fe14Cr1.5Zr_800C1h, Fe14Cr_500C26h, Fe14Cr1.5Zr_900C1h and Fe14Cr_900C1h alloy samples, respectively. (a2-f2) The corresponding HRTEM images of $\mathrm{Fe}-14 \mathrm{Cr}$ alloys at peak $\mathrm{He}$ concentration area. (a3-f3) Selected area diffraction patterns near peak $\mathrm{He}$ concentration area. Depth profile of displacement damage and He concentration is seen in (f1), calculated by SRIM. (a3-f3) 
(a)

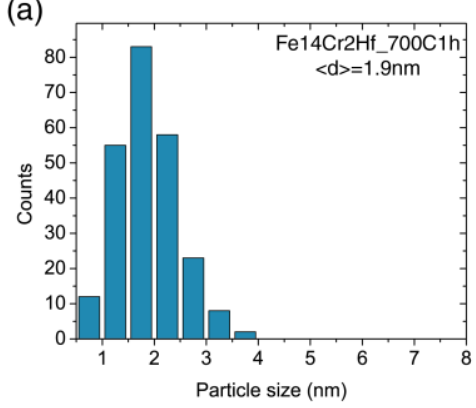

(d)

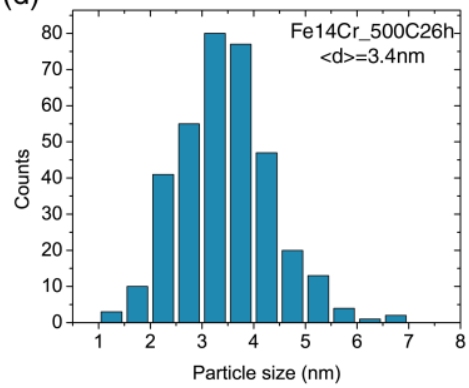

(b)

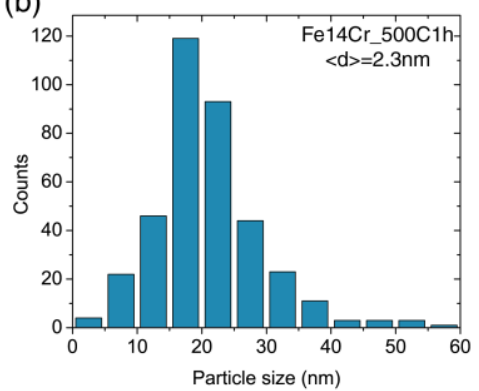

(e)

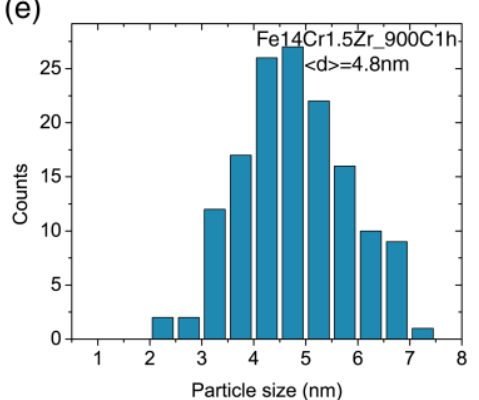

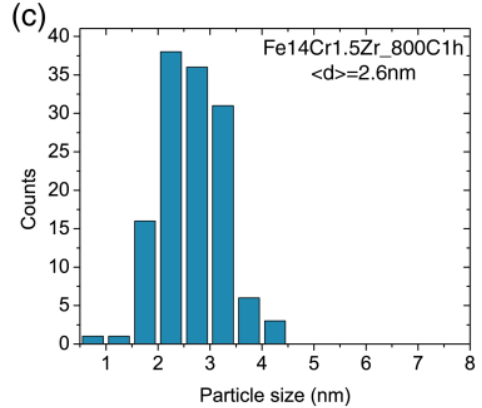

(f)

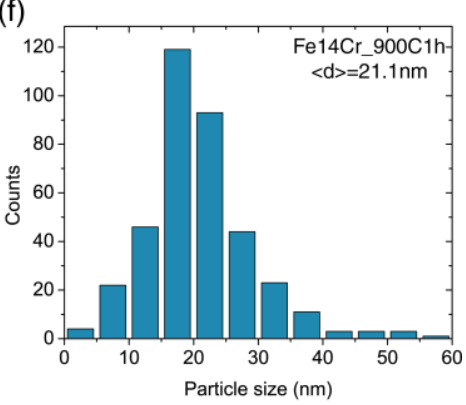

Fig. 7. Particle size histogram of (a) hafnium oxide in Fe14Cr2Hf_700C1h, (b) chromium oxide in Fe14Cr_500C1h, (c) zirconium oxide in Fe14Cr1.5Zr_800C1h, (d) chromium oxide in Fe14Cr_500C26h, (e) zirconium oxide in Fe14Cr1.5Zr_900C1h, (f) chromium oxide in Fe14Cr_900C1h. 

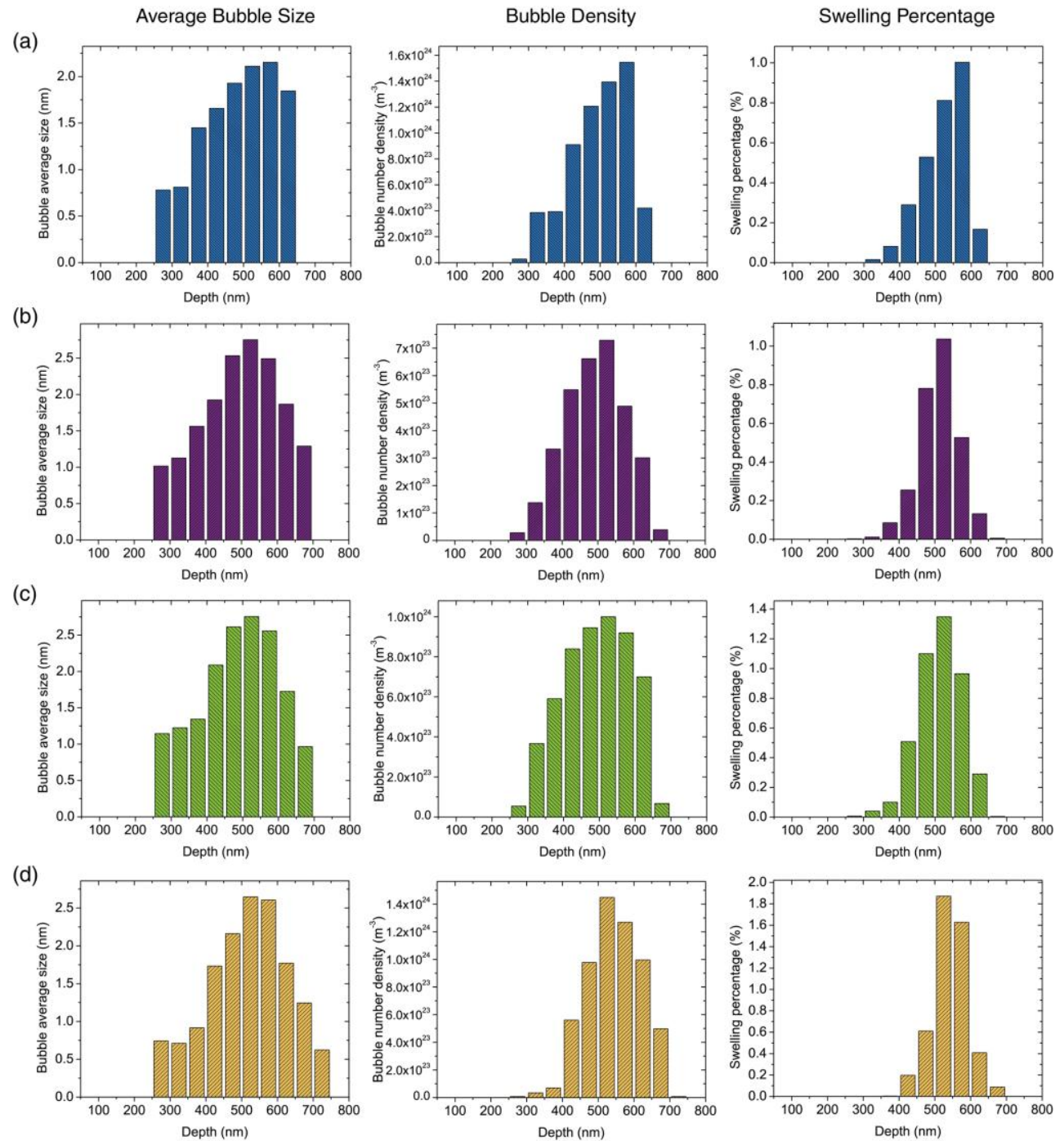

(e)
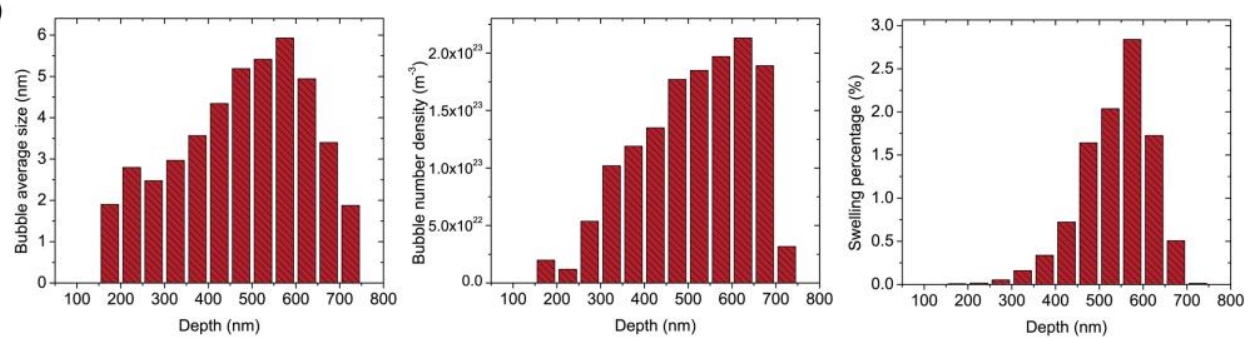

(f)
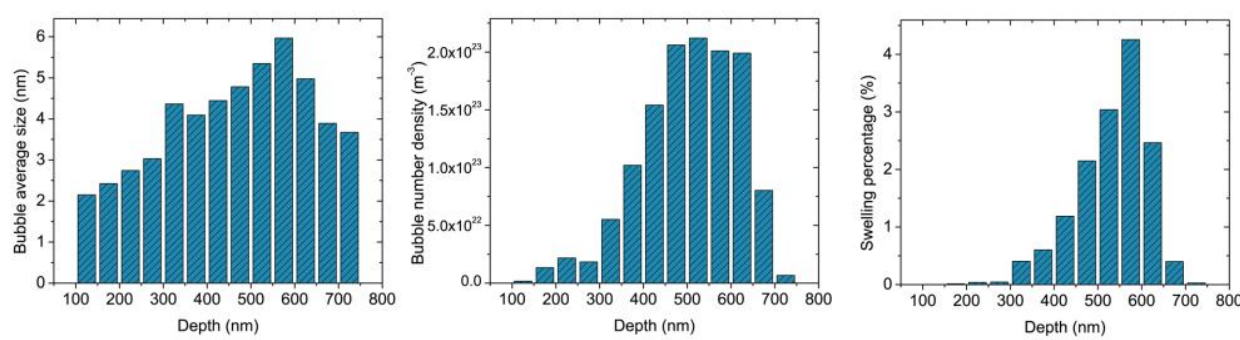

Fe14Cr2Hf_700C1h Fe14Cr_500C1h Fe14Cr_500C26h

Fig. 8. Depth profile of void swelling, He bubble size and bubble density in (a)

Fe14Cr2Hf_700C1h, (b) Fe14Cr_800C1h, (c) Fe14Cr1.5Zr_800C1h, (d) Fe14Cr_500C26h, (e) Fe14Cr1.5Zr_900C1h, (f) Fe14Cr_900C1h alloy samples subject to $200 \mathrm{keV} \mathrm{He}$ irradiation. 
(a)

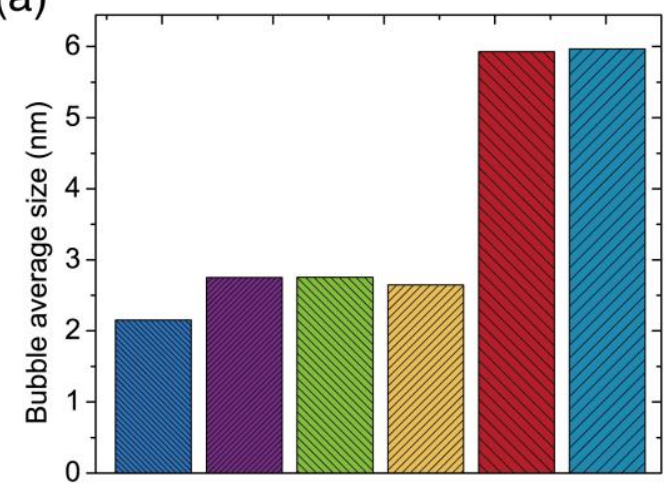

(c)

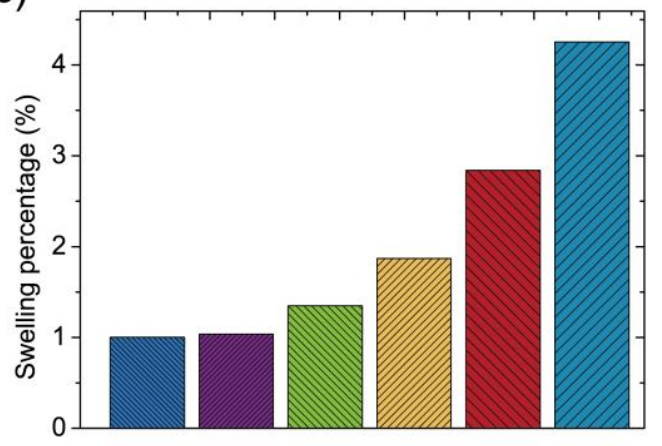

(b)

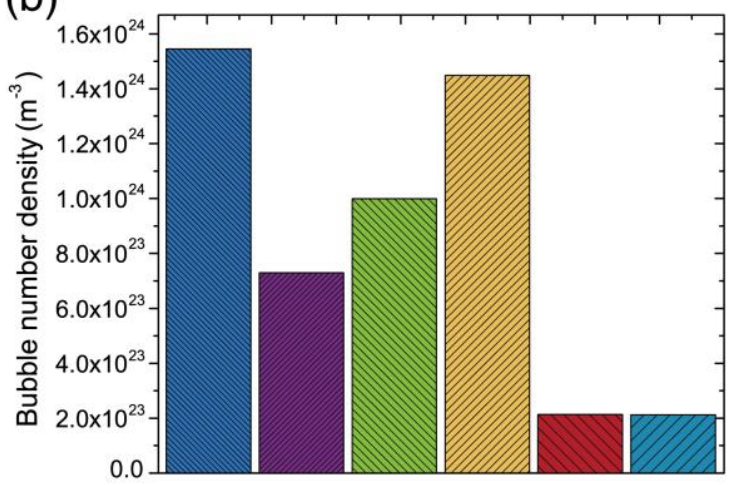

(d)

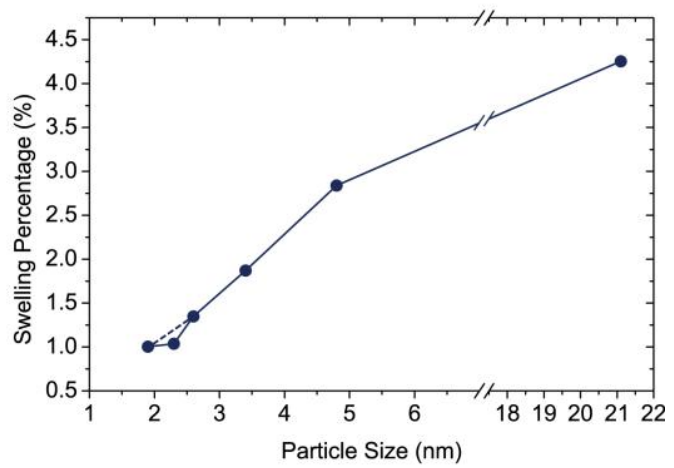

WF14Cr2Hf_700C1h WFe14Cr_500C1h VIDA Fe14Cr_500C26h

WFe14Cr_900C1h MIVFe14Cr1.5Zr_800C1h $\square$ Fe14Cr1.5Zr_900C1h

Fig. 9. Comparison of the maximum value of (a) void swelling, (b) He bubble size and (c) bubble density among Fe14Cr2Hf_700C1h, Fe14Cr_500C1h, Fe14Cr1.5Zr_800C1h, Fe14Cr_500C26h, Fe14Cr1.5Zr_900C1h, and Fe14Cr_900C1h alloy samples subject to $200 \mathrm{keV}$ He irradiation. (d) The relationship between nano-oxide particle size and the void swelling in $\mathrm{Fe}-14 \mathrm{Cr}$ alloys. 